\title{
Sleep Disorders and Obesity: How Related are These Patologies?
}

\author{
M Rodríguez Pérez* \\ ${ }^{1}$ Faculty of Biochemistry and Envieronmental Sciences, University of Castilla-La Mancha, Spain
}

Submission: November 13, 2019; Published: December 16, 2019

*Corresponding author: M Rodríguez Pérez, Faculty of Biochemistry and Envieronmental Sciences, University of Castilla-La Mancha, Avda. Carlos III S/N. 45071, Toledo, Spain

\begin{abstract}
Sleep is an integral part of everyday life, a biological need that allows to restore the physical and psychological functions. It has been, and continues being, one of the enigma of scientific research, and even today, we have great doubts about it. It was to be considered a passive phenomenon in which apparently nothing seems to happen, but thanks to the appearance of techniques for measuring brain electrical activity, now, is a state of dynamic consciousness in which we can get to have such an active brain activity, as in the vigil, and in which major modifications of the functioning of the organism occur, like changes in blood pressure, heart and respiratory rate, body temperature, hormonal secretion, among others. Several evidences suggest a strong link between problems in sleep and an increment in obesity, specially in children. Furthermore, another patologies are assocciated with both obesity and poor sleep habits. It is absolutelly clear that more studies are needed in order to evaluate the potencial effect of shorter times in bed on obesity and in this way, combat the epidemic of that disease
\end{abstract}

Keywords: Sleep disordes; Obesity; Children; New lifestyles

Abbreviations: OSA: Obstructive Sleep Apnea; SSD: Short Sleep Duration; TIB: Time in Bed

\section{Introduction}

Obesity is an enourmus public health problem and is associated with different comorbidities, such as sleep-related disorders, affecting cardiovascular and metabolic markers too $[1,2]$. Furthermore, prevalence of obesity has increased to epidemic proportions; in 2016, more than 1900 million adults had overweight and more than 650 million, obesity. Additionally, mortality rate among overweight and obese people is higher than underweight people [3]. Therfore, it is crucial to focus on several factors related to obesity which could be modified in order to achieve preventive interventions, and there are differents studies that demostrate the importance of sleep quality and quantity in the development of that disease $[4,5,6]$. Sleep is a basic human need, being a fundamental biological process and not only to maintain an optimal psychological functionality, but also the physiolocial functionality of important systems such as endocrine, immune, cardiovascular and neurological. Therefore, sleep has a crucial impact on the health and quality of life of people [7].

In the last years, it has observed a reduction in the quality and quantity of sleep directly related to new lifestyles, which include less time to rest, mainly for the use of techonology until late at night as well as an-abuse of caffeinated beverages $[8,9]$.
Sleep deprivation usually provokes two situations, such as day time sleepiness and increased appetite after hours. Sleeping less than six hours causes drowsiness that lasts throughout the day. In obese people, the level of fatigue increases, which means they are less motivated to continue with their daily training plan and set a side one of the most effective resources for losing weight. On the other hand, sleep deprivation influences appetite. When you try to sleep and you can not, you tend to eat and drink after hours, and sometimes, the chosen food is hypercaloric and also, sugary drinks. Therefore, the fatigue makes to eat more to obtain more energy and that, does not facilitate a better sleep at the same time that does no help you lose weight [10].

According to that, it was demostrated that individuals who report short sleep duration (SSD) (less than 7 hours per night) have a higher body mass index as well as a higher prevalence of obesity than those who report adequate sleep (7-8 hours per night) [11]. Focussing on the impact of sleep duration on the appetite-regulating hormones, Spiegel et al reported that in young normal weight men after a period of sleep restriction, 4 hours time in bed (TIB), leptin levels was reduced compare to 10h TIB [12]. However, hormones are not the unique factors which control food intake in humans since various reasons why we eat are not related 
to hunger: stress, fatigue or boredoom, for example. Having said that, it is important to highlight that sleep poor quality or short duration is directly related to obesity in children [13] whist in adults is no so clear.

A systematic review of studies published between October 2004 and October 2010, distinguished consistency of the results in children while in adults was the opposite [14]. A possible explanation of that could be the fact that the need for sleep decreases with age. It is well known that children need more hours of sleep and a deprivation of that may produce important effects on their metabolism. Therefore, there may be other factor like mood or strees which could mediate the relationship between sleep duration and obesity in adults, and this is the reason which explains the big differences finding in the studies [6]. Interestly, it was described that the link between poor sleep and obesity was stronger in adult males than in females [15].

\section{Obesity disease related to sleep}

Obstructive sleep apnea (OSA) is the most common form of sleep-disordered breathing and is characterized by total or partial collapse of the upper airway and is an important consequence of obesity [16]. Moreover, several studies have demostrated that a descreases in the severity of OSA is a direct effect of a diminution in weight loss [17]. On the other hand, imaging studies has also suggest that intramuscular deposition of fat in the tongue narrows the upper airway being this a direct consequence of the obesity [18]. Other important disease related to obesity and sleep is the depression. However, the directionality is not clear. In several studies, depression is related to obesity in both adolescentes and adults $[19,20]$.

Obesity may contribute to depression through the increase of inflammation and the insulin resistance while depression may also inflence obesity through poor lifestyle behaviours, like limited physical activity related to sedentary lifestyle or low quality diet $[21,22,23]$. Besides comorbidities, obesity may have a direct effect on sleep. Different clinical researches have shown that obese patients without OSA are more prone to suffer daytime sleepiness and night time sleep distubances compared to patients with normal weight $[24,25]$. Moreover, it has been demostrated that obesity has a direct effect on sleep mechanism since it has been identified as a risk factor for excessive day time sleepiness in a independent way of depression and OSA.

\section{Conclusion}

In our modern society, due to new lifestyles, bad sleep habits like shorter sleep duration, are increasing both adults and children. Numerous studies have reported the association between this short sleep duration and other problems related with obesity. Having said that, it seems that in children the link between poor sleep and obesity is more clear. Furthermore, other obesity comorbidities associated with sleep have been described, as OSA and depression. May be, one easy solution to that problem could be a delay in the school start times, in order to improve sleep health in children and it could be used to analyse the effect of this on obesity risk.

\section{References}

1. Passali D, Corallo G, Petii A, Longini M, Passali FM, et al. (2016) A comparative study on oxidative stress role in nasal breathing impariment and obstructive sleep apnoea syndrome. Acta Otorhinolaryngol Ital 36(6): 490-495.

2. Basnet S, Merikanto I, Lahti T, Mannisto S, Laatikainen T et al. (2016) Associations of common chronic non-communicable diseases and medical conditions with sleep-related problems in a population-based health examination study. Sleep Sci 9(3): 249-254.

3. World Health Organization (2019) Obesity and overweight.

4. Matricciani L, Olds T, Petkov J (2012) In search of lost sleep: secular trends in the sleep time of school-aged children and adolescents. Sleep Med Rev 16(3): 203-211.

5. Watson NF, Badr MS, Belenky G, Bliwise DL, Buxton OM, et al. (2015) Recommended amount of sleep for a healthy adult: a joint consensus statement of the American Academy of Sleep Medicine and Sleep Research Society. Sleep 38(6): 843-844.

6. Lombardo C (2016) Sleep and obesity: an introduction. Eating and Weight Disorders - Studies on Anorexia, Bulimia and Obesity 21(1): $1-4$.

7. Cardenas Villarreal VM, Hernandez Carranco RG (2012) The role of sleep as obesity risk Development. Scientif Enferm. 20: 14-18.

8. Chaput JP, Klingenberg L, Sjodin A (2010) Do all sedentary activities lead to weight gain: sleep does not. Curr Opin Clin Nutr Metab Care 13(1): 601-607.

9. Gamble AL, D Rozario AL, Bartlett DJ, Williams S, Bin YS, et al. (2014) Adolescent sleep patterns and night-time technology use: results of the Australian Broad casting Corporation's Big Sleep Survey. PLoS One 9(11): e111700.

10. St Onge MP (2017) Sleep-obesity relation: underlying mechanisms and consequences for treatment. Obesity Rev 18(1): 34-39.

11. Spiegel K, Tasali E, Penev P, Van Cauter E (2004) Brief communication: sleep curtailment in healthy young men is associated with decreased leptin levels, elevated ghrelin levels, and increased hunger and appetite. Ann Intern Med 141: 846-850.

12. Liu J, Zhang A, Li L (2012) Sleep duration and overweight/ obesity in children: review and implications for pediatric nursing. Spec Pediatr Nurs 17(3): 193-204.

13. Magee L, Hale L (2012) Longitudinal associations between sleep duration and subsequent weight gain: a systematic review. Sleep Med Rev 16(3): 231-241.

14. Storfer-Isser A, Patel SR, Babineau DC, Redline S (2011) Relation between sleep duration and BMI varies by age and sex in youth age 8-19. Pediatr Obes 7(1): 53-64.

15. Ogilvie RP, Patel SR (2017) The Epidemiology of Sleep and Obesity. Sleep Health 3(5): 383-388.

16. Mitchell LJ, Davidson ZE, Bonham M, O Driscoll DM, Hamilton GS, et al. (2014) Weight loss from lifestyle interventions and severity of sleep apnoea: a systematic review and meta-analysis. Sleep Med 15(10): 1173-1183. 
17. Kim AM, Keenan BT, Jackson N, Chan EL, Satley B, et al. (2014) Tongue fat and its relationship to obstructive sleep apnea. Sleep 37(10): 16391648.

18. Faith MS, Butryn M, Wadden TA, Fabricatore A, Nguyen AM et al. (2011) Evidence for prospective associations among depression and obesity in population-based studies. Obesity rev. 12(5): e438-453.

19. Luppino FS, de Wit LM, Bouvy PF, Stijnen T, Cuijpers P, et al. (2010) Overweight, obesity, and depression: a systematic review and metaanalysis of longitudinal studies. Arch Gen Psychiatry 67(3): 220-229.

20. Moheet A, Mangia S, Seaquist ER (2015) Impact of diabetes on cognitive function and brain structure. Ann N Y Acad Sci 1353: 60-71.

21. Atlantis E, Ball K (2008) Association between weight perception and psychological distress. Int J Obes. 32(4): 715-721.

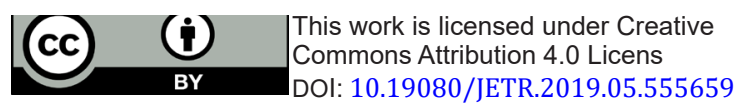

22. Shoelson SE, Herrero L, Naaz A. (2007) obesity, inflammation, and insulin resistance. Gastroenterology 132(6): 2169-2180.

23. Vgontzas AN, Bixler EO, Tan TL, Kantner D, Martin LF, et al. (1998) Obesity without sleep apnea is associated with daytime sleepiness. Arch Intern Med 158(12): 1333-1337.

24. Resta O, Foschino Barbaro MP, Bonfitto P, Giliberti T, Depalo A, et al. (2003) Low sleep quality and daytime sleepiness in obese patients without obstructive sleep apnoea syndrome. J Intern Med. 253(5): 536-543.

25. Bixler EO, Vgontzas AN, Lin HM, Calhoun SL, Vela-Bueno A, et al. (2005) Excessive daytime sleepiness in a general population sample: the role of sleep apnea, age, obesity, diabetes, and depression. J Clin Endocrinol Metab 90(8): 4510-4515.

Your next submission with Juniper Publishers
will reach you the below assets
- Quality Editorial service
- Swift Peer Review
- Reprints availability
- E-prints Service
- Manuscript Podcast for convenient understanding
- Global attainment for your research
- Manuscript accessibility in different formats
( Pdf, E-pub, Full Text, Audio)
- Unceasing customer service
Track the below URL for one-step submission
https://juniperpublishers.com/online-submission.php

